\title{
Release of tissue inhibitor of metalloproteinase-2 from alginate microcapsule encapsulating genetically engineered cells
}

This article was published in the following Dove Press journal:

International Journal of Nanomedicine

5 November 2013

Number of times this article has been viewed

\author{
Yeon Seong Kim ${ }^{1, *}$ \\ Young-II Jeong ${ }^{2, *}$ \\ Shu-Guang Jin ${ }^{2}$ \\ Jian $\mathrm{Pei}^{2}$ \\ Min Wen ${ }^{2}$ \\ In-Young Kim' \\ Kyung-Sub Moon' \\ Tae-Young Jung' \\ Hyang-Hwa Ryu ${ }^{2}$ \\ Shin Jung ${ }^{1-3}$ \\ 'Department of Neurosurgery, \\ ${ }^{2}$ Brain Tumor Research Laboratory, \\ ${ }^{3}$ Chonnam National University \\ Research Institute of Medical \\ Sciences, Chonnam National \\ University Hwasun Hospital and \\ Medical School, Jeollanam-do, Korea \\ *These authors contributed equally \\ to this work
}

Background: In this study, 293T cells were genetically engineered to secrete tissue inhibitor of metalloproteinase-2 (TIMP2) and encapsulated into alginate microcapsules to continuously release TIMP2 protein.

Methods: The anti-invasive potential of the microcapsules was studied in vitro using brain tumor cells. The TIMP2 gene was transfected to $293 \mathrm{~T}$ cells, and genetically engineered 293 TIMP 2 cells were encapsulated into alginate microcapsules. Release of TIMP2 protein was detected with Western blot analysis and the anti-invasive potential against U87MG cells was tested using gelatin zymography and a Matrigel assay.

Results: Cell viability within the alginate microcapsules was maintained at a cell density of $5 \times 10^{6}$. Because polycationic polymers are helpful for maintaining the mechanical strength of microcapsules with good cell viability, the alginate microcapsules were reinforced with chitosan $(0.1 \% \mathrm{w} / \mathrm{v})$. Expression of TIMP2 protein in cell lysates and secretion of TIMP2 into the conditioned medium was confirmed by Western blot analysis. Alginate microcapsules encapsulating 293TIMP2 cells released TIMP2 protein into the medium efficiently, where the TIMP2 protein participated in degradation of the matrix metalloproteinase- 2 enzyme and inhibited invasion of U87MG cells.

Conclusion: Alginate microcapsules encapsulating 293TIMP2 cells are promising candidates for anti-invasive treatment of glioma.

Keywords: $293 \mathrm{~T}$ cells, tissue inhibitor of metalloproteinase-2, alginate microcapsule, therapeutic protein

\section{Introduction}

Brain tumors develop in tens of thousands of adults each year, and the incidence has increased rapidly in recent decades. ${ }^{1-3}$ Brain tumors are specifically distinguished from other tumors based on their invasive properties, ie, local invasion of brain tumors is more common than metastasis. It is rare that glioma cells enter the subarachnoid space and/or intravasate into the cerebral microvasculature. ${ }^{4}$ Further, the grade of brain tumor is not significantly correlated with the degree of local invasion. Therefore, the invasive properties of high-grade gliomas in the surrounding normal brain tissue are lethal factors. Infiltrated brain tumor cells, which often escape surgical resection, frequently lead to tumor recurrence. ${ }^{5,6}$ The infiltrative nature of high-grade gliomas is responsible for much of the morbidity and mortality associated with these tumors. Surgical debulking of the tumor often constitutes only a temporizing measure, because microscopic-infiltrated foci of tumors will eventually lead to recurrence, often in areas that are surgically inaccessible. As a result, patients afflicted with high-grade gliomas
Correspondence: Shin Jung

Department of Neurosurgery, Chonnam National University Hwasun Hospital, 160 Ilsim-ri, Hwasun-eup, Hwasun-gun, Jeollanam-do, 519-809, Korea

Tel +82613797666

Fax +82 6I 3797673

Email sjung@chonnam.ac.kr 
face a poor prognosis, with less than $10 \%$ surviving beyond 2 years. ${ }^{1-6}$

Among various mechanisms, degradation of the extracellular matrix by proteolytic enzymes is a classic feature of the invasive process. Such features are commonly expressed by the infiltrating cells of brain tumors. Matrix metalloproteinases (MMPs), which can degrade almost all components of the extracellular matrix, are known to have an important role in invasion of brain tumors. ${ }^{7-11}$ Because the mechanism of local invasion by malignant glioma cells is distinguished from the mechanisms underlying proliferation, therapeutic strategies against invasive behavior are needed. Among the various kinds of MMPs, activated gelatinase A (MMP-2) has a major role in glioma invasion. ${ }^{12-16}$ Van Meter et al reported that tissue inhibitors of MMPs (TIMPs) block the action of MMPs and significantly decrease invasiveness. ${ }^{16}$ Further, when glioma cells are transfected with gene constructs encoding TIMP-1 or TIMP2, invasion is decreased. ${ }^{14}$ Merzak et al also reported that TIMP2 expression in malignant glioma cell lines decreases the ability to invade. ${ }^{15}$

Alginate microcapsules encapsulating cells that are genetically engineered to continuously produce a therapeutic protein (endostatin) have been reported to inhibit angiogenesis of gliomas. ${ }^{17-19}$ Read et al reported that genetically engineered human embryonic kidney cells producing endostatin, an angiogenesis inhibitor, could be encapsulated in alginate beads that released endostatin for several months. ${ }^{18,19}$ Further, these alginate beads effectively inhibited development of vascular structures in an animal brain tumor model.

In the current study, 293T was genetically modified to secrete TIMP2 and these genetically engineered $293 \mathrm{~T}$ cells were encapsulated in alginate microcapsules. We expected that alginate beads encapsulating 293TIMP2 cells would produce TIMP2 continuously and that this protein could inhibit invasion of brain tumor cells in vitro.

\section{Materials and methods Materials}

Alginic acid sodium salt, ethidium homodimer-1, calcein AM, and calcium chloride were purchased from Sigma Chemical Co (St Louis, MO, USA). Chitosan 5 was purchased from Wako Pure Chemical Co (Osaka, Japan). Chitosan was pretreated with acid solution to make watersoluble chitosan as follows: chitosan was dissolved in $0.1 \mathrm{~N}$ $\mathrm{HCl}$ solution for 3 hours, then dialyzed (using 12,000 g/mol dialysis tubes) against excess deionized water to remove $\mathrm{HCl}$ salt with exchange of water at 3-hourly intervals for 2 days. The chitosan solution was then lyophilized or used for bead preparation. [N-2-hydroxyethylpiperazine- $\mathrm{N}^{\prime}$-2ethanesulfonic acid] was purchased from Amresco (Solon, $\mathrm{OH}, \mathrm{USA})$.

\section{Preparation of alginate beads}

293E or 293 TIMP2 cells were maintained under exponential growth conditions in Dulbecco's Modified Eagle's Medium (DMEM) supplemented with 10\% fetal bovine serum. Cells were trypsinized and harvested by centrifugation. The cells were resuspended in sodium alginate-saline $(1.2 \% \mathrm{wt} / \mathrm{vol})$ to a final ratio of $5 \times 10^{6}$ cells $/ \mathrm{mL}$ of alginate. The suspension was dropped through a $23 \mathrm{G}$ needle into a solution of HEPESbuffered calcium chloride (13 mM HEPES, 1.5\% [wt/vol] $\mathrm{CaCl}_{2}$ [pH 7.4]; Sigma Chemical Co) with chitosan $1 \mathrm{mg} / \mathrm{mL}$ and allowed to gel for 20 minutes. Chitosan was used to reinforce the alginate microcapsule. ${ }^{20}$ The alginate beads were washed three times with HEPES solution (13 mM), then cultured in DMEM supplemented with $10 \%$ fetal bovine serum in a $5 \% \mathrm{CO}_{2}$ incubator.

\section{Cells and cell culture}

U87MG glioma cells and 293T cells were purchased from the American Type Culture Collection (Manassas, VA, USA). Cells were maintained in DMEM supplemented with $10 \%$ fetal bovine serum.

\section{Viability of encapsulated cells}

Viability of the encapsulated cells was measured using Alamar Blue ${ }^{\mathrm{TM}}$ (AbD Serotec, Kidlington, Oxford, UK) as reported by Baruch et al. ${ }^{21} \mathrm{~A}$ volume of microcapsules equivalent to 100,000 encapsulated cells at the day of encapsulation was placed in a 24-plate. The microcapsules were incubated in $1 \mathrm{~mL}$ of $10 \%(\mathrm{v} / \mathrm{v})$ Alamar Blue for 4 hours, after which two $100 \mu \mathrm{L}$ samples of conditioned medium from each well were distributed to a 96-well plate and read using a microplate fluorometer.

\section{TIMP2 transfection procedure}

According to the sequence of GenBank, the primers were designed and synthesized by Bioneer Corporation (Deajeon, Korea) as follows: sense primer, 5'-ATGGGCGCCGCGGCCCGCACC-3'; and antisense primer, 5'-TTATGGGTCCTCGATGTCGAGAAACTCC-3'.

The 293 T cells were maintained under exponential growth conditions in DMEM supplemented with 10\% fetal bovine serum in the absence of antibiotics. The optimum cell density for transfection is normally between $50 \%$ and $80 \%$ confluence for adherent cells. The pcDNA ${ }^{\mathrm{TM}} 6 /$ myc-HisA empty 
vector and $\mathrm{pcDNA}^{\mathrm{TM}} 6 / \mathrm{myc}$-HisA-TIMP2 (both Bioneer Corporation, Daejeon, Korea) were transfected into $293 \mathrm{~T}$ cells using Lipofectamine ${ }^{\text {TM }} 2000$ transfection reagent (Invitrogen, Carlsbad, CA, USA). The transfectants are referred to herein as 293E and 293TIMP2, respectively. Cells in serum-free DMEM were mixed with $6 \mathrm{mg}$ of plasmid DNA and $6 \mathrm{~mL}$ of Lipofectamine 2000 serum-free medium according to the manufacturer's protocol. After a 5 -hour incubation at $37^{\circ} \mathrm{C}$ in $5 \% \mathrm{CO}_{2}$, the transfection mixture was replaced with DMEM supplemented with $10 \%$ fetal bovine serum. After 48 hours of incubation, the medium was replaced with DMEM containing $10 \%$ fetal bovine serum and $12 \mathrm{mg} / \mathrm{mL}$ blasticidin, and cultured in $\mathrm{CO}_{2}$ incubator. The blasticidin clones were isolated, and the level of expression of TIMP2 protein was determined by Western blot analysis. The stable transfectants were maintained in DMEM supplemented with $10 \%$ fetal bovine serum and $6 \mathrm{mg} / \mathrm{mL}$ blasticidin.

\section{Live/dead cell staining}

Live/dead cell staining was performed according to a previously reported method. ${ }^{22}$ The live/dead cell staining working solution was prepared as follows: $2 \mathrm{mM}$ ethidium homodimer-1 solution was diluted to $4 \mu \mathrm{M}$ in 0.1 M phosphate-buffered saline ( $\mathrm{pH} 7.4$ ); calcein AM stock solution was then added to this solution (final concentration, $2 \mu \mathrm{M}$ calcein AM). Alginate beads was washed with phosphate-buffered saline three times, and incubated with live/dead staining working solution at $37^{\circ} \mathrm{C}$ for 30 minutes in dark conditions. Samples were observed under a confocal laser scanning microscope (TCS-SP2; Leica, Wetzlar, Germany). Calcein AM produced green fluorescencelabeled live cells and ethidium homodimer-1 produced red fluorescence-labeled dead cells.

\section{Western blotting}

For Western blotting, cells cultured in $10 \mathrm{~cm}$ dishes were washed with $0.1 \mathrm{M}$ phosphate-buffered saline ( $\mathrm{pH}$ 7.4) and $2 \mathrm{~mL}$ of serum-free DMEM was added. After one or 3 days, the medium was harvested. For 3-day culture, $1 \mathrm{~mL}$ of DMEM was supplemented at day 2 to avoid drying of the culture medium. The cells were harvested by centrifugation and washed three times with phosphate-buffered saline.

Cells were lysed in a lysis buffer (50 mM Tris [ $\mathrm{pH} 8.0]$, $5 \mathrm{mM}$ ethylenediamine tetra-acetic acid, $150 \mathrm{mM} \mathrm{NaCl}$, $0.5 \%$ deoxycholic acid, $0.1 \%$ sodium dodecyl sulfate, $1 \%$ NP-40, $1 \mathrm{mM}$ phenylmethylsulphonyl fluoride, and $1 \mathrm{mg} / \mathrm{mL}$ protease inhibitor cocktail). The protein concentrations were determined using a protein assay kit (Bio-Rad, Hercules,
CA, USA). Next, $50 \mu \mathrm{g}$ of protein from the whole cell lysates or conditioned medium was separated by $12 \%$ sodium dodecyl sulfate polyacrylamide gel electrophoresis and transferred to a polyvinylidene difluoride membrane (Pall Corporation, Port Washington, NY, USA). Subsequently, the membrane was incubated for 2 hours at room temperature in a solution of TBST (10 mM TrisCl [pH 8.0], $150 \mathrm{mM} \mathrm{NaCl}$, and 0.05\% Tween 20) supplemented with 5\% nonfat dry milk, and probed overnight at $4{ }^{\circ} \mathrm{C}$ with mouse anti-TIMP 2 antibody 1 (1:1,000 dilution). The bound antibodies were visualized with an anti-mouse second antibody (1:20,000 dilution) conjugated with horseradish peroxidase using enhanced chemiluminescence reagents (Amersham Biosciences, Sunnyvale, CA, USA). $ß$-actin was used as an internal control. We used densitometer (1-Dmain) software to estimate the level of expression of TIMP2.

\section{Matrigel invasion assay}

Prior to performing the Matrigel ${ }^{\circledR}$ invasion assay, U87MG cells were exposed to 293E and 293TIMP2-encapsulated alginate beads (number of beads approximately 100) for 2 days. The Matrigel invasion assay was performed using a Transwell chamber, as reported previously, ${ }^{23}$ and $8 \mu \mathrm{m}$ pore size polycarbonate membranes (Costar, Cambridge, MA, USA) coated with serum-free DMEM-diluted extracellular matrix (Matrigel, DMEM to extracellular matrix [3:1]; Becton Dickson, Bedford, MA, USA). Cells were seeded at a density of $5 \times 10^{4}$ cells in $350 \mu \mathrm{L}$ of serum-free DMEM in the upper compartment of the Transwell, and allowed to invade polycarbonate membranes for 24 hours. The lower chamber was filled with DMEM that contained $10 \%$ fetal bovine serum. After incubation, the noninvaded cells on the upper surface of the membrane were removed, and the invaded cells on the lower surface of the membrane were stained with Hemacolor ${ }^{\circledR}$ (Merck, Darmstadt, Germany). The number of invaded cells in four randomly selected microscopic fields per membrane was counted.

\section{Gelatin zymography}

Gelatin zymography was performed, as reported previously. ${ }^{24}$ The U87MG cells were seeded onto $10 \mathrm{~cm}$ tissue culture plates and cultured in $5 \% \mathrm{CO}_{2}$ at $37^{\circ} \mathrm{C}$ in the presence of serum. The cells were grown and enriched on a culture plate (approximately $70 \%$ of the plate). Subsequently, the medium was replaced by $3 \mathrm{~mL}$ of serum-free DMEM per plate containing $>100$ alginate beads encapsulating 293E cells or 293TIMP2 cells. After 48 hours of incubation, the conditioned medium was collected and ultracentrifuged to remove 
the cell debris. After this procedure, the cells were harvested to study intracellular MMP expression, as described below. The centrifuged medium was used for the gelatin zymography assay, as follows: $50 \mu \mathrm{g}$ of the total protein from the solution was mixed with the sample buffer (50 mM Tris-Cl, $2 \%$ sodium dodecyl sulfate, $0.1 \%$ bromophenol blue, and $10 \%$ glycerol); the protein was electrophoresed on $8 \%$ denaturing sodium dodecyl sulfate polyacrylamide gels containing $2 \mathrm{mg} / \mathrm{mL}$ of gelatin (type A, Sigma); the gel was washed three times for 30 minutes in $2.5 \%$ Triton $\mathrm{X}-100$, and incubated for 20 hours at $37^{\circ} \mathrm{C}$ in $50 \mathrm{mM}$ of a buffer solution containing Tris- $\mathrm{Cl}$ (pH 7.5), $10 \mathrm{mM} \mathrm{CaCl}$, and $200 \mathrm{mM} \mathrm{NaCl}$; and the gel was stained with Coomassie Brilliant Blue R-250 (0.2\% Coomassie Brilliant Blue R-250, 20\% methanol, and $10 \%$ acetic acid in $\left.\mathrm{H}_{2} \mathrm{O}\right)$, then destained $(20 \%$ methanol and $10 \%$ acetic acid in $\mathrm{H}_{2} \mathrm{O}$ ).

\section{Statistical analysis}

The Student's $t$-test (Statgraphics, SigmaPlot) was used to assess the statistical differences between experimental groups. $P<0.05$ was taken as being statistically significant.

\section{Results}

\section{Transfection of TIMP2-}

\section{overexpressed 293T cells}

293 T cells were cloned with the TIMP2 gene. An empty vector without the TIMP2 gene was also transfected to 293 T cells (293E). As shown in Figure 1, 293TIMP2 cells expressed TIMP 2 protein based on Western blotting, and the conditioned medium also showed TIMP2 protein, while $293 \mathrm{E}$ cells did not express TIMP2.

\section{Preparation of alginate microcapsule encapsulating 293TIMP2 cells}

Alginate microcapsules were prepared with the transfected cells; $5 \times 10^{6}$ cells were encapsulated into alginate microcapsules and their size is shown in Figure 2A. As shown in Figure 2A, the average size of the microcapsule was $<800 \mu \mathrm{m}$ in the $293 \mathrm{E}$ and 293 TIMP2 microcapsules. The viability of cells in the microcapsules is shown in Figure 2B. Even though the viability of 293TIMP2 cells was less than that of the $293 \mathrm{~T}$ and $293 \mathrm{E}$ cells in the microcapsules, cell viability was not significantly changed. Live and dead cells were stained after 4 weeks of culture, as shown in Figure 2C. After 4 weeks of culture, the cells encapsulated in the alginate microcapsules showed good viability.

To demonstrate continuous secretion of TIMP2 from the alginate microcapsules, the microcapsules encapsulating 293TIMP2 cells were cultured in serum-free medium and secretion of TIMP2 was checked by Western blotting. As shown in Figure 3, the intensity of TIMP2 was increased on day 2 of culture compared with day 1 , even though TIMP 2 expression was not significantly changed on day 3 . These results indicate continuous release of TIMP 2 from the microcapsule and TIMP 2 accumulation in the medium. The activity of the TIMP2 protein released from the alginate microcapsules encapsulating 293E and 293TIMP2 cells against MMP-2 is shown in Figure 4. Alginate microcapsules encapsulating 293TIMP2 cells might affect the MMP-2 secretion from U87MG cells, ie, MMP-2 activity at day 2 and 3 was significantly lower than that of day 1, as shown in Figure 4. These results might be due to the fact that TIMP2 secreted from microcapsules may affect activation of proMMP-2 and then active MMP-2 can be degraded, which reduces the total amount of MMP-2.

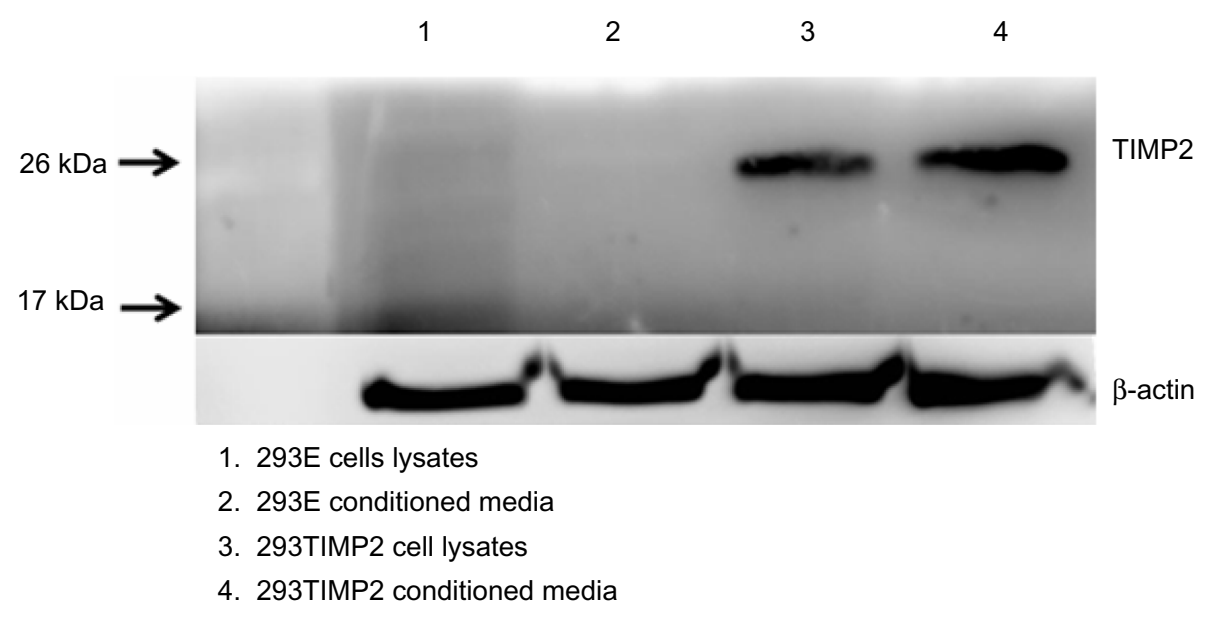

Figure I Western blot analysis of TIMP2 expression on 293T cells.

Abbreviation: TIMP2, tissue inhibitor of metalloproteinase-2. 
A

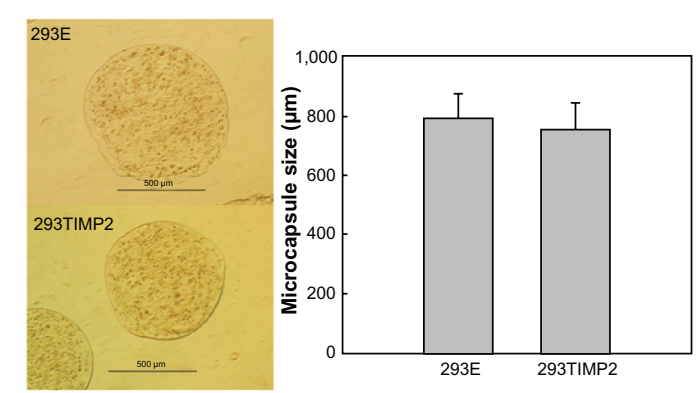

B

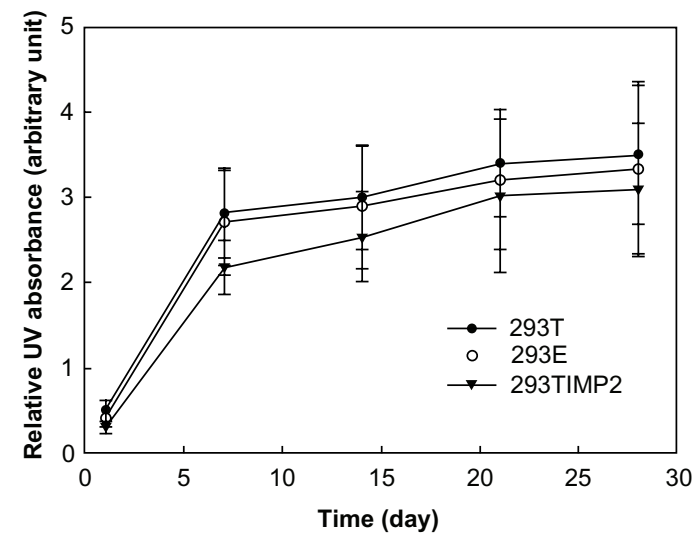

C

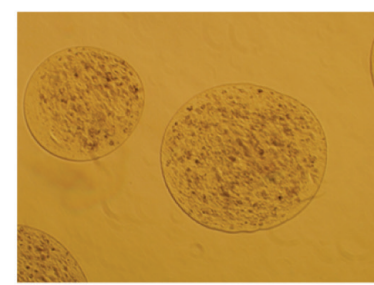

Merge
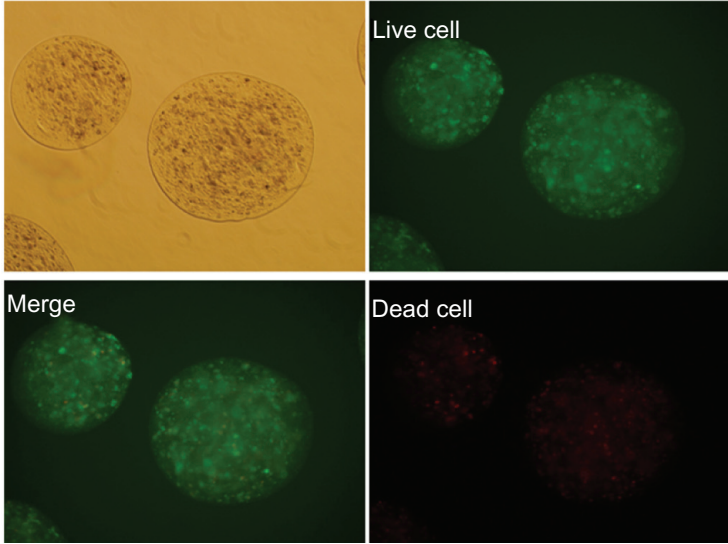

Dead cell

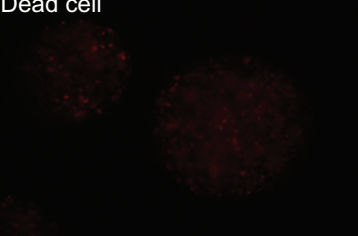

Figure 2 (A) Mean diameter of alginate microcapsules encapsulating 293TIMP2 cells (B) Viability of 293TIMP2 cells in alginate microcapsules. (C) Live/dead cell staining of 293TIMP2 microcapsules. The microcapsules were cultured in Dulbecco's Modified Eagle's Medium containing 10\% fetal bovine serum for 4 weeks. Results are expressed as the mean (standard deviation) of three separate experiments.

Abbreviation: 293TIMP2, 293T cells genetically modified to secrete tissue inhibitor of metalloproteinase- 2 .

MMP-2 activity was not significantly changed by treatment with 293E microcapsules. Figure 5 shows the effect of alginate microcapsules encapsulating 293TIMP2 cells on invasion of U87MG cells. More than 100 microcapsules were treated with U87MG cells for 2 days. Invasion of U87MG cells was tested with the Matrigel assay. As shown in Figure 5, the number of cells invading the lower surface of the membrane was decreased significantly when 293TIMP2 microcapsules were treated. These results indicate that alginate microcapsules encapsulating
293TIMP2 cells are prime candidates for inhibiting invasion by brain tumors.

\section{Discussion}

Local invasiveness of tumor cells is one of the main issues in the treatment of brain tumors; no correlation between degree of local invasion and grade of brain tumor has been demonstrated. ${ }^{4}$ Infiltrated cells which escape surgical resection frequently lead to recurrence of tumors after surgical debulking. ${ }^{5,6}$

In tumor cell invasion, a three-step process has been proposed, ${ }^{7-10}$ as follows: receptor-mediated matrix adhesion; degradation of matrix by tumor-secreted hydrolytic enzymes (such as MMPs); and movement of tumor cells into the newly created space. Degradation of the extracellular matrix by activated gelatinase A (MMP-2) or gelatinase B (MMP-9) in brain tumors is an important factor in invasion of brain tumors. ${ }^{7-16}$ MMP-2 is known to have a strong influence on glioma invasion. ${ }^{12,13}$ Otherwise, TIMP-1 and TIMP2 are known to block the action of MMP-2 and MMP-9, which significantly decreases the invasiveness of tumor cells. Overexpression of TIMP2 in glioma cells results in decreased expression of MMP, which decreases the invasiveness of glioma cells. ${ }^{14,15}$ For example, Huang et al reported that mRNA levels of MMP-2 and membrane type I MMP were significantly reduced in glioma cells. ${ }^{25}$ Further, Lu et al reported that adenovirus-mediated transfection of TIMP2 to U87MG cells reduces relative MMP-2/9 activity and suppresses the invasiveness of U87MG cells. ${ }^{26}$ Noninvasive cells such as MCF-7 show high levels of TIMP2 and very low levels of MMP-2, while highly invasive cells such as U87MG cells express MMP-2 together with TIMP2. ${ }^{27}$ Wisniewski et al also reported on the correlation between invasiveness of glioma cells, MMP-2 activity, and TIMP2 expression. ${ }^{28}$ Bernardo and Fridman reported that TIMP2 is known to regulate MMP-2 activity in the extracellular environment of tumor tissues after pro-MMP-2 activation by membrane type 1 MMP. ${ }^{29}$ They showed that net MMP-2 activity correlates with the level of TIMP2 expression. From this point of view, inhibition of MMP expression by TIMP2 is an ideal target for decreasing tumor cell invasion.

In recent decades, microcapsules or microbeads using sodium alginate has received considerable attention for the treatment of tumors. ${ }^{19,30}$ Read et al reported that cells genetically engineered to produce endostatin and encapsulated in alginate beads released endostatin continuously for several months. ${ }^{19}$ They also showed that endostatin released from beads inhibited vascularization in a rat BT4C glioma model 


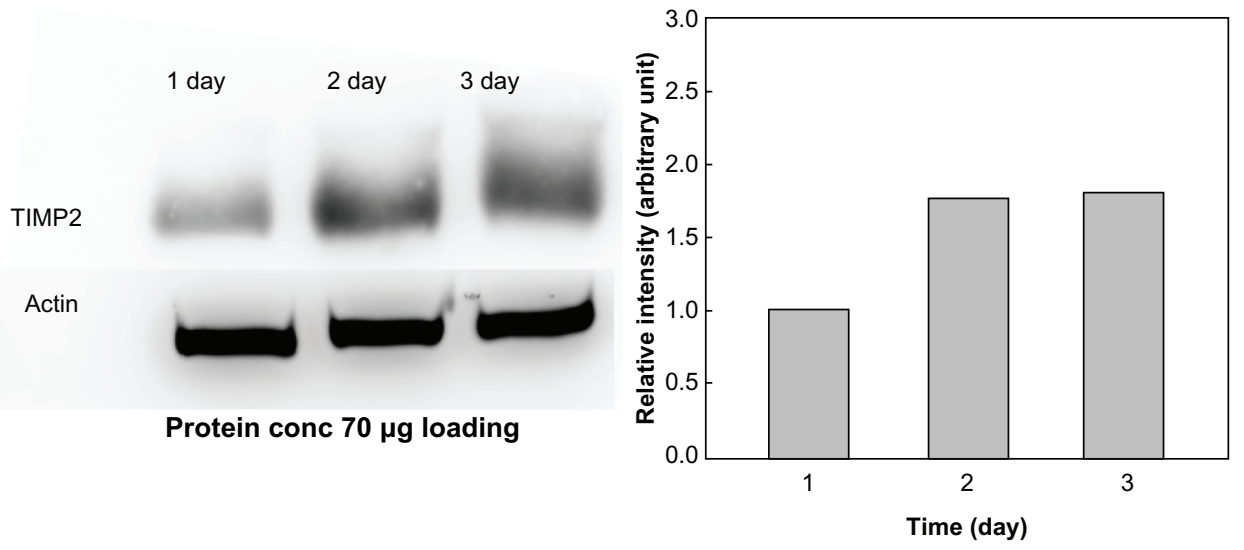

Figure 3 Secretion of TIMP2 from 293TIMP2 alginate microcapsules. The extent of TIMP2 secretion was analyzed by Western blotting. Abbreviations: TIMP2, tissue inhibitor of metalloproteinase-2; 293TIMP2, 293T cells genetically modified to secrete tissue inhibitor of metalloproteinase-2; conc, concentration.

and prevented growth of solid tumors. ${ }^{19}$ Further, release of endostatin from alginate beads was maintained over 12 months. ${ }^{30}$ Another group also reported that continuous release of endostatin from microcapsules encapsulating genetically engineered cells is effective in inhibiting vascularization and tumor growth using an U87MG xenograft mouse model. ${ }^{17}$

Antiangiogenesis therapy using continuous release of endostatin has been successful. ${ }^{17,19}$ However, there are several reports on the side effects, ie, antiangiogenesis therapy using endostatin can enhance glioma invasion. Lamszus et al reported that antiangiogenesis therapy using an orthotopic model significantly enhanced the number and total area of small satellite tumors clustered around the primary tumor mass. ${ }^{31}$ Thus, antiangiogenesis therapy can enhance glioma invasion. From these points of view, we have focused on inhibition of glioma invasion. TIMP2 expression is inversely correlated with MMP-2 expression. We determined that $293 \mathrm{~T}$ cells (human embryonic kidney cells) are genetically modified with the TIMP2 gene to secrete TIMP2 protein. The 293T cell, ie, the normal human embryonic kidney cell, was selected for genetic modification because it has several advantages for this purpose. ${ }^{32,33}$ For example, the rapid growth rate of 293 cells is suitable for producing therapeutic protein. Ease of transfection and stable maintenance of transformed cells are other reasons for this choice. For all these reasons, researchers have used HEK293 cells for genetic modification and production of therapeutic proteins. ${ }^{17-19}$ As shown in Figure 1, the TIMP2 clone of 293T cells (293TIMP2) clearly expressed TIMP2 protein in cell lysates and the conditioned medium.

Alginate microcapsules were used to encapsulate 293 TIMP2 cells. Among various polymeric materials,

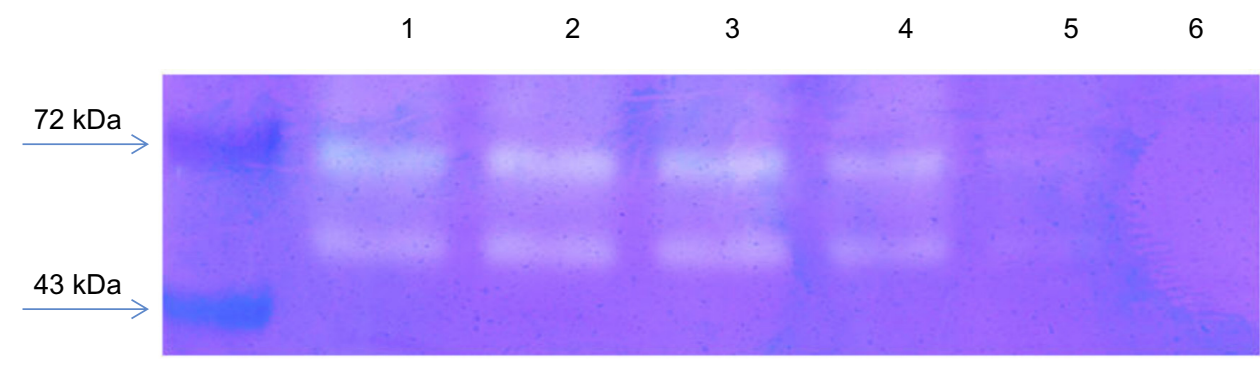

1. $293 \mathrm{E}$ microcapsule -1 day

2. $293 \mathrm{E}$ microcapsule -2 day

3. 293E microcapsule -3 day

4. 293TIMP2 microcapsule -1 day

5. 293TIMP2 microcapsule -2 day

6. 293TIMP2 microcapsule -3 day

Figure 4 Gelatin zymography. U87MG cells were cultured in $10 \mathrm{~cm}$ dishes (cell density $70 \%-80 \%$ of dish area) with Dulbecco's Modified Eagle's Medium (DMEM) containing $10 \%$ fetal bovine serum. U87MG cells cultured with serum-free DMEM were treated with 293E or 293TIMP2 microcapsules ( $>100$ microcapsules).

Abbreviations: TIMP2, tissue inhibitor of metalloproteinase-2; 293TIMP2, 293T cells genetically modified to secrete tissue inhibitor of metalloproteinase-2. 


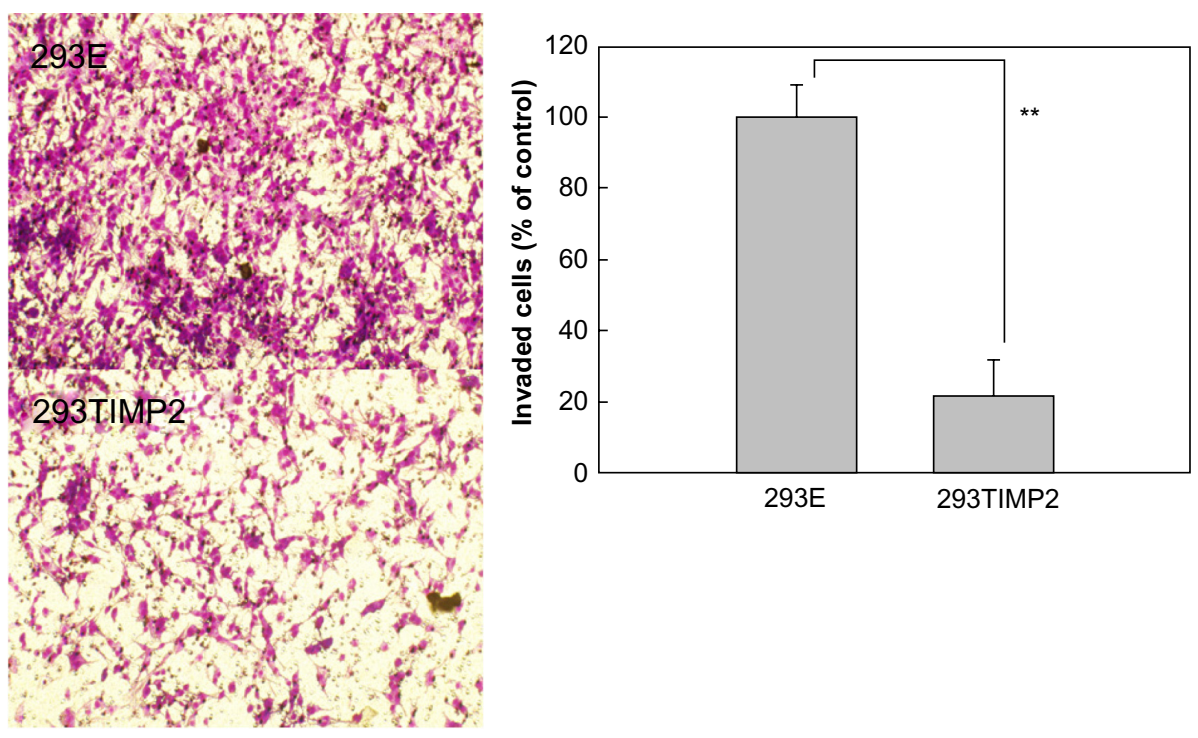

Figure 5 Effect of 293E and 293TIMP2 microcapsules on invasiveness of U87MG cells. The invasion test was performed using the Matrigel ${ }^{\circledR}$ assay. U87MG cells cultured in $10 \mathrm{~cm}$ dishes were exposed to $293 \mathrm{E}$ or 293 TIMP2 microcapsules ( $>100$ microcapsules) for 2 days. Next, $5 \times 10^{6}$ cells were seeded into the upper chamber and the cells invading the lower surface were stained with Hemacolor ${ }^{\circledR}$. The number of invading cells was counted in four randomly selected microscopic fields per membrane. These experiments were repeated five times and are expressed as the mean (standard deviation).

Note: $* * P<0.001$.

Abbreviations: TIMP2, tissue inhibitor of metalloproteinase-2; 293TIMP2, 293T cells genetically modified to secrete tissue inhibitor of metalloproteinase-2.

alginate is acceptable for cell encapsulation since it is biocompatible, and has good morphologic/mechanical properties and biochemical characteristics. ${ }^{34,35}$ Further, because alginate forms hydrogel microcapsules with the aid of cationic chemicals such as $\mathrm{Ca}^{2+}$ or $\mathrm{Mg}^{2+}$ in aqueous solution, the alginate microcapsule is suitable for maintenance of cell viability and secretion of therapeutic protein. A number of researchers have used alginate for encapsulation of genetically engineered cells or sustained release of proteins. ${ }^{17-19,36}$ Read et al reported that empty alginate capsules or alginate capsules encapsulating 293 cells cause negligible irritation in the mouse brain and have good biological compatibility. ${ }^{19}$ Further, they argued that viability of 293 cells in alginate capsules was adequately maintained in vivo. Our results show that capsule size and cell viability in 293TIMP2 microcapsules was not significantly different from that of 293E microcapsules, as shown in Figure 2. Figure 2C shows live and dead cell staining for 293TIMP2 microcapsules after 4 weeks. As shown in Figure 2C, 293TIMP2 cells were viable in alginate microcapsules. Specifically, alginate microcapsules encapsulating 293TIMP2 cells showed increased TIMP2 density on Western blotting analysis and TIMP2 protein density in the medium was increased according to the time course. These results indicate that alginate microcapsules encapsulating 293TIMP2 cells are able to release TIMP2 protein continuously. This phenomenon was demonstrated using U87MG cells, as seen in Figures 4 and 5.
As shown in Figure 4, when alginate microcapsules encapsulating 293TIMP2 cells were added to U87MG cell cultures, the intensity of MMP-2 decreased, while alginate microcapsules encapsulating 293E cells did not significantly affect MMP-2 activity, indicating that MMP-2 activity in U87MG cells is decreased by TIMP2 protein secreted from alginate microcapsules. The decreased MMP-2 activity in U87MG cells may affect invasiveness. As shown in Figure 5, invasion was significantly decreased in U87MG cells treated with 293TIMP2 microcapsules. Hur et al reported finding high activity of MMP-2 and weak expression of TIMP2 mRNA in malignant glioma, indicating an imbalance of TIMP2/ MMP-2 in glioma cells. ${ }^{37}$ Our results indicate that alginate microcapsules encapsulating 293TIMP2 cells are superior candidates for anti-invasive treatment of glioma.

\section{Conclusion}

$293 \mathrm{~T}$ cells were genetically engineered to secrete TIMP2 (293TIMP2). 293TIMP2 cells were encapsulated into alginate microcapsules to continuously release TIMP2 protein. The anti-invasive potential of the microcapsules was studied in vitro using brain tumor cells. The TIMP2 gene was transfected to $293 \mathrm{~T}$ cells, and genetically engineered 293TIMP2 cells were encapsulated into alginate microcapsules. The TIMP2 protein released was detected using Western blot analysis and its anti-invasive potential in U87MG cells was tested with gelatin zymogra- 
phy and a Matrigel assay. Cell viability within the alginate microcapsules was adequately maintained at a cell density of $5 \times 10^{6}$. Because polycationic polymers are helpful in maintaining the mechanical strength of microcapsules with good cell viability, the alginate microcapsules were reinforced with chitosan $(0.1 \% \mathrm{w} / \mathrm{v})$. Expression of TIMP2 protein in the cell lysates and secretion of TIMP2 into the conditioned medium was confirmed with Western blot analysis. Alginate microcapsules encapsulating 293TIMP2 cells released TIMP2 protein into the medium effectively and the TIMP2 protein released was effective in inhibiting MMP-2 expression and invasion of U87MG cells. In conclusion, alginate microcapsules encapsulating 293TIMP2 cells are promising candidates for anti-invasive treatment of glioma.

\section{Acknowledgment}

This study was supported by a grant (CRI 10065-1) from the Chonnam National University Hospital Research Institute of Clinical Medicine.

\section{Disclosure}

The authors report no conflicts of interest in this work.

\section{References}

1. Greig NH, Ries LG, Yancik R, Rapoport SI. Increasing annual incidence of primary malignant brain tumors in the elderly. J Natl Cancer Inst. 1990;82:1621-1624.

2. Mahaley MS Jr, Mettlin C, Natarajan N, Laws ER Jr, Peace BB. National survey of patterns of care for brain-tumor patients. $J$ Neurosurg. 1989;71:826-836.

3. Walker AE, Robins M, Weinfeld FD. Epidemiology of brain tumors: the national survey of intracranial neoplasms. Neurology. 1985;35: 219-226.

4. Schoenberg BS. Epidemiology of primary intracranial neoplasms: disease distribution and risk factors. In: Salcman M, editor. Neurobiology of Brain Tumors (Concepts in Neurosurgery). Baltimore, MD: Williams \& Wilkins; 1991;4.

5. Bernstein JJ, Woodard CA. Glioblastoma cells do not intravasate into blood vessels. Neurosurgery. 1995;36:124-132.

6. Ruoslahti E. Brain extracellular matrix. Glycobiology. 1996;6: 489-492.

7. Cockett MI, Birch ML, Murphy G, Hart IR, Docherty AJ. Metalloproteinase domain structure, cellular invasion and metastasis. Biochem Soc Trans. 1994;22:55-57.

8. Sato H, Takino T, Okada Y, et al. A matrix metalloproteinase expressed on the surface of invasive tumour cells. Nature. 1994;370:61-65.

9. Vincent TL, Gatenby RA. An evolutionary model for initiation, promotion, and progression in carcinogenesis. Int J Oncol. 2008;32: 729-737.

10. Woodhouse EC, Chuaqui RF, Liotta LA. General mechanisms of metastasis. Cancer. 1997;80:1529-1537.

11. Wojtowicz-Praga SM, Dickson RB, Hawkins MJ. Matrix metalloproteinase inhibitors. Invest New Drugs. 1997;15:61-75.

12. Abe T, Mori T, Kohno K, et al. Expression of $72 \mathrm{kDa}$ type IV collagenase and invasion activity of human glioma cells. Clin Exp Metastasis. 1994;12:296-304.
13. Deryugina EI, Bourdon MA, Luo GX, Reisfeld RA, Strongin A. Matrix metalloproteinase-2 activation modulates glioma cell migration. J Cell Sci. 1997;110:2473-2482.

14. Matsuzawa K, Fukuyama K, Hubbard SL, Dirks PB, Rutka JT. Transfection of an invasive human astrocytoma cell line with a TIMP-1 cDNA: modulation of astrocytoma invasive potential. J Neuropathol Exp Neurol. 1996;55:88-96.

15. Merzak A, Parker C, Koochekpour S, Sherbet GV, Pilkington GJ. Overexpression of the $18 \mathrm{~A} 2 / \mathrm{mts} 1$ gene and down-regulation of the TIMP2 gene in invasive human glioma cell lines in vitro. Neuropathol Appl Neurobiol. 1994;20:614-619.

16. Van Meter T, Rooprai HK, Rucklidge GJ, Pilkington GJ. Functional blocking with TIMP-1 and anti-alpha-V integrin: evidence for cooperation of MMPs and integrins in glioma invasion in vitro. Anticancer Res. 1997; 17:1051.

17. Joki T, Machluf M, Atala A, et al. Continuous release of endostatin from microencapsulated engineered cells for tumor therapy. Nat Biotechnol. 2001;19:35-39.

18. Read TA, Farhadi M, Bjerkvig R, et al. Intravital microscopy reveals novel antivascular and antitumor effects of endostatin delivered locally by alginate-encapsulated cells. Cancer Res. 2001;61:6830-6837.

19. Read TA, Sorensen DR, Mahesparan R, et al. Local endostatin treatment of gliomas administered by microencapsulated producer cells. Nat Biotechnol. 2001;19:29-34.

20. Sankalia MG, Mashru RC, Sankalia JM, Sutariya VB. Reversed chitosan-alginate polyelectrolyte complex for stability improvement of alpha-amylase: optimization and physicochemical characterization. Eur J Pharm Biopharm. 2007;65:215-232.

21. Baruch L, Benny O, Gilert A, Ukobnik M, Ben Itzhak O, Machluf M. Alginate-PLL cell encapsulation system co-entrapping PLGAmicrospheres for the continuous release of anti-inflammatory drugs. Biomed Microdevices. 2009;11:1103-1113.

22. Haque T, Chen H, Ouyang W, et al. Superior cell delivery features of poly(ethylene glycol) incorporated alginate, chitosan, and poly-L-lysine microcapsules. Mol Pharm. 2005;2:29-36.

23. Jin SG, Jeong YI, Jung S, Ryu HH, Jin YH, Kim IY. The effect of hyaluronic acid on the invasiveness of malignant glioma cells: comparison of invasion potential at hyaluronic acid hydrogel and matrigel. J Korean Neurosurg Soc. 2009;46:472-478.

24. Lim SH, Jeong YI, Moon KS, et al. Anticancer activity of PEGylated matrix metalloproteinase cleavable peptide-conjugated adriamycin against malignant glioma cells. Int J Pharm. 2010;387: 209-214.

25. Huang HP, Shih YW, Wu CH, Lai PJ, Hung CN, Wang CJ. Inhibitory effect of penta-acetyl geniposide on C6 glioma cells metastasis by inhibiting matrix metalloproteinase- 2 expression involved in both the PI3K and ERK signaling pathways. Chem Biol Interact. 2009;181:8-14.

26. Lu W, Zhou X, Hong B, Liu J, Yue Z. Suppression of invasion in human U87 glioma cells by adenovirus-mediated co-transfer of TIMP2 and PTEN gene. Cancer Lett. 2004;214:205-213.

27. Chernov AV, Sounni NE, Remacle AG, Strongin AY. Epigenetic control of the invasion-promoting MT1-MMP/MMP-2/TIMP2 axis in cancer cells. J Biol Chem. 2009;284:12727-12734.

28. Wisniewski P, Ellert-Miklaszewska A, Kwiatkowska A, Kaminska B. Non-apoptotic Fas signaling regulates invasiveness of glioma cells and modulates MMP-2 activity via NFkappaB-TIMP2 pathway. Cell Signal. 2010;22:212-220.

29. Bernardo MM, Fridman R. TIMP2 (tissue inhibitor of metalloproteinase-2) regulates MMP-2 (matrix metalloproteinase-2) activity in the extracellular environment after pro-MMP-2 activation by MT1 (membrane type 1)-MMP. Biochem J. 2003;374:739-745.

30. Bjerkvig R, Read TA, Vajkoczy P, et al. Cell therapy using encapsulated cells producing endostatin. Acta Neurochir Suppl. 2003;88: $137-141$.

31. Lamszus K, Kunkel P, Westphal M. Invasion as limitation to antiangiogenic glioma therapy. Acta Neurochir Suppl. 2003;88:169-177. 
32. Backliwal G, Hildinger M, Hasija V, Wurm FM. High-density transfection with HEK-293 cells allows doubling of transient titers and removes need for a priori DNA complex formation with PEI. Biotechnol Bioeng. 2008;99:721-727.

33. Thomas P, Smart TG. HEK293 cell line: a vehicle for the expression of recombinant proteins. J Pharmacol Toxicol Methods. 2005;51: 187-200.

34. Raj NK, Sharma CP. Oral insulin - a perspective. J Biomater Appl. 2003;17:183-196.
35. Webber RE, Shull KR. Strain dependence of the viscoelastic properties of alginate hydrogels. Macromolecules. 2004;37:6153-6160.

36. Han MR, Kwon MC, Lee HY, et al. pH-dependent release property of alginate beads containing calcium carbonate particles. J Microencapsul. 2007;24:787-796.

37. Hur JH, Park MJ, Park IC, et al. Matrix metalloproteinases in human gliomas: activation of matrix metalloproteinase-2 (MMP-2) may be correlated with membrane-type-1 matrix metalloproteinase (MT1-MMP) expression. J Korean Med Sci. 2003;15:309-314.
International Journal of Nanomedicine

\section{Publish your work in this journal}

The International Journal of Nanomedicine is an international, peerreviewed journal focusing on the application of nanotechnology in diagnostics, therapeutics, and drug delivery systems throughou the biomedical field. This journal is indexed on PubMed Central,

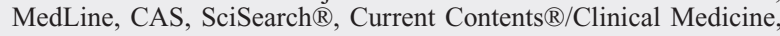

\section{Dovepress}

Journal Citation Reports/Science Edition, EMBase, Scopus and the Elsevier Bibliographic databases. The manuscript management system is completely online and includes a very quick and fair peer-review system, which is all easy to use. Visit http://www.dovepress.com/ testimonials.php to read real quotes from published authors.

Submit your manuscript here: http://www.dovepress.com/international-journal-of-nanomedicine-journal 